\title{
A EDUCAÇÃO ESCOLAR NO PAÍS EM CONSTRUÇÃO: UBERABA NO PERÍODO DA PRIMEIRA REPÚBLICA BRASILEIRA ${ }^{1}$
}

\author{
Jean Felipe Pimenta Borges \\ Sandra Mara Dantas ${ }^{2}$ \\ Universidade Federal do Triângulo Mineiro (UFTM)
}

\begin{abstract}
RESUMO
O período da Primeira República no Brasil foi profundamente influenciado pelos ideais de modernidade e progresso, característicos do século XIX. Entre os elementos mobilizados pelo governo republicano, a educação escolar foi um dos responsáveis pela difusão desses valores pelo país. O presente trabalho tem por objetivo tecer algumas considerações acerca da organização do ensino escolar na cidade de Uberaba - MG no período anterior à criação do primeiro grupo escolar. Para tanto foram utilizadas fontes de arquivo legislativo e impressos que compreendem os anos entre 1889 e 1908. Compreendemos que houve uma preocupação com a questão do ensino e esforços no sentido de organizar as escolas na cidade, porém, devido a diversas questões, sem alcançar toda a população como se aventava.
\end{abstract}

Palavras-chave: Primeira República, Uberaba, Educação Escolar, Modernidade.

\section{THE SCHOOL EDUCATION IN A DEVELOPING COUNTRY: UBERABA IN THE FIRST PERIOD OF BRAZILIAN REPUBLIC}

\begin{abstract}
The period of First Republic in Brazil was deeply affected by modernity and progress ideals, characteristic of $19^{\text {th }}$ century. Among the elements mobilized by republic government, the school education was on responsible for diffusion this values by the country. So, this scientific paper has objective to make some considerations about the organization of the school teaching in Uberaba city, Minas Gerais state, in the period before the creation at the first scholar group. For this, was used to sources of legislative file and printed that understand the years among 1889 and 1908. Understanding that there was a preoccupation with teaching question and efforts to organize schools in the city, however, due to various issues, has not reached the entire population as said.

Keywords: First Republic, Uberaba, School Education, Modernity.
\end{abstract}

\section{Introdução:}

Pensando a cidade de Uberaba (MG) no período de organização da República no Brasil, o presente trabalho tem por objetivo tecer algumas considerações sobre a atuação do poder público municipal - no período representado pela Câmara Municipal - na organização do ensino escolar.

No período que vai da Proclamação da República à criação do primeiro grupo escolar em Uberaba - marco na organização de um modelo escolar -, trata de um período caracterizado por diversas mudanças impulsionadas pelos ideais de modernidade e progresso e, por um debate acerca da importância e do papel da escola naquela sociedade. 
A educação escolar foi encarada como uma importante ferramenta utilizada na construção da nação naquele momento e tinha entre seus objetivos: superar as contradições herdadas de períodos anteriores, reduzir as diferenças regionais e formar o povo brasileiro para o exercício da cidadania, orientando o país para o progresso e para a civilização. Nesse sentido, cabe pensar a atuação do Estado na garantia da educação e difusão desses valores.

Em nosso caso, Uberaba foi escolhida por se constituir, no período privilegiado pelo estudo - 1889 a 1908 -, cidade primaz no Triângulo Mineiro, polarizando as demais, como espécie de referência com significativa movimentação comercial, entrada de migrantes e imigrantes, configuração do espaço urbano e melhorias na infraestrutura e em serviços. Também, a qualidade de seu arquivo permite o acesso à documentação referente ao período.

\section{Modernidade e Progresso: o contexto da época}

O século XIX é representativo de um mundo em transformação. Permeado pelos ideais de modernidade, progresso e civilidade, foi um período que experimentou um momento "peculiar de ebulição criativa" (CAMPOS, 2004), porque trazia consigo novas possibilidades, avanços tecnológicos, perspectivas de aceleração do tempo, descobertas e inovações.

Dessa forma, o período de transição entre o século XIX e o século XX, ficou marcado pela mudança na relação entre homem e natureza que era repensada pela ótica dos avanços técnico-científicos, pelo avanço das fábricas e pela promoção de outra noção de tempo, marcada pelo uso do relógio e pelo ritmo frenético das cidades movidas pelas marias-fumaça e motores à combustão. Tudo isso promovia a vida nas cidades que lentamente ia ganhando força em relação à vida no campo e estabelecia novas relações entre as pessoas.

Esses ideais que chacoalhavam o mundo também se pautavam pelo signo da contradição. Havia a valorização das cidades num mesmo momento que as levas populacionais expulsas do campo não encontravam as condições ideais de sobrevivência e, considerando o movimento de higienização e modernização das cidades, apresentavam-se como um grande problema para o Estado. No caso do Brasil, a dicotomia entre campo e cidade representava o paradoxo do país que se queria moderno e civilizado, mas que economicamente ainda era profundamente rural.

Os progressos na área da saúde contrastavam com o aumento da poluição gerada pelas fábricas e com os surtos de doenças. Os extremos de pobreza e riqueza eram realçados por um modelo econômico que pregava o direito de enriquecimento pelo trabalho, ainda que não promovesse a igualdade de condições. Tudo era efêmero, mutável e paradoxal. (CAMPOS, 2004)

Apesar de todas essas questões, o otimismo ante as realizações do homem ainda prevaleciam e novos modos de viver, pensar e produzir iam se difundindo pelo mundo, adaptando-se as realidades locais mas, com o olhar voltado para tudo que acontecia na Europa. Para as elites brasileiras que se reorganizavam sob a República, esse momento foi aproveitado nos discursos que buscavam a legitimidade do novo regime e em todo lado se ouvia o desejo de modernidade. Dentre as questões aventadas, a que nos interessa era o debate sempre presente acerca da necessidade de investimento em educação e de ampliação do sistema escolar no país, que aparecia como uma das preocupações dos governos na Primeira República. 
No entanto, havia muito a ser feito. O número de analfabetos era altíssimo e em grande medida, as instituições de ensino existentes se encontravam em poder da iniciativa privada e, o ritmo de ampliação da rede escolar pública era lento, medido pela disponibilidade de recursos e pelo tempo de construção de novas escolas. Por outro lado, mesmo com essas dificuldades o número de matrículas aumentava, na medida em que se difundia a compreensão de que a escola era o lugar privilegiado para a formação do cidadão que os grupos intelectualizados desejavam para o país e por despertar a população para o progresso e civilização. (GATTI Jr. \& INÁCIO FILHO, 2005)

Imbuída dessa "tarefa civilizadora", a educação tornou-se estandarte de defesa nos discursos políticos em todo o país, sob a argumentação de que a difusão do conhecimento arrancaria a população brasileira da ignorância e da irracionalidade e asseguraria o progresso. Para tanto, estruturou-se um campo de ação política, de feições liberais, com dezenas de regulamentações legais e práticas referentes ao cotidiano escolar. $\mathrm{O}$ "entusiasmo pela educação" fomentou campanhas públicas pelo tema e novas ideias pedagógicas que pudessem estabelecer as bases da nação republicana e a nova mentalidade acordada com o progresso. Em suma, parcelas da elite viam a educação como modo de superação da condição de atraso. (CAMPOS, 2004; GATTI Jr. e INÁCIO FILHO, 2005)

$\mathrm{Na}$ esteira dessas discussões, na última década do século XIX, Minas Gerais realizou uma reforma descentralizadora da educação, dividindo a província em dez circunscrições. Nessa reforma, a ênfase recaiu sobre a profissionalização do professor que deveria empreender esforços para "formar o caráter dos alunos" e para tanto se exigia que possuísse uma moral ilibada, "o ideal de professor envolvia qualidades e valores voltados para o novo modelo urbano-industrial” (BORGES, 2005).

\subsection{A cidade de Uberaba}

A cidade de Uberaba foi se constituindo ao longo do século XIX e início do XX como importante referência dessas ideias, no interior do Brasil:

Dentro do esforço modernizador do Brasil, momento em que a cultura urbana passou a ser parâmetro de comparação entre o "civilizado" e o "não-civilizado", "moderno" e "antigo", Uberaba assumiu para si a responsabilidade de ser o centro dispersor de civilidade em uma região quase deserta. (RISCHITELLI, 2005)

Uberaba também sempre esteve muito próxima aos debates realizados na capital e às novidades que chegavam da Europa. Situada em uma região atravessada por vários caminhos, a cidade foi aquela que mais se beneficiou da intersecção dos sistemas de transporte e de deslocamento que atravessavam à região. Por volta de 1840 pode-se afirmar que já existia o urbano, porque a vida ia se tornando mais movimentada e o contato com outras regiões mais frequente. Como entreposto comercial, as atividades econômicas se diversificaram, verificando-se a existência de vários comerciantes, mascates, vendeiros e outros; a intensificação do fluxo populacional; a demanda por novos serviços.

A prática do comércio foi uma das principais práticas econômicas da cidade por grande parte do século XIX, sendo reforçada com a chegada da Companhia Mogiana, em 1889. Esse fato promoveu a cidade à uma espécie de entreposto por onde circulava grande quantidade de mercadorias. A chegada dos trilhos também intensificou as relações entre a cidade e o estado de São Paulo, a níveis que se tornaram preocupantes para o governo estadual mineiro. Porém, também trouxe prosperidade pelo comércio com os mercados de Goiás e Mato Grosso, perdidos em seguida, com a ampliação da linha férrea à cidade de Uberabinha (atual Uberlândia) e posteriormente Araguari. 
Assim, na última década do século XIX, no período de organização da República, a cidade passou então por uma reorganização econômica, voltando-se para a agricultura e a pecuária e fez as primeiras experiências com o gado Zebu que, até os dias de hoje, tem uma grande importância econômica para a cidade. O historiador Augusto Rischiteli sugere que a indústria zebuína acentuou o processo de urbanização em desenvolvimento desde a chegada da ferrovia:

Representando a fomentação provocada pela riqueza adquirida, os proprietários e os comerciantes de zebu, recorreram a arquitetos, engenheiros e construtores alemães, espanhóis, portugueses e, principalmente, italianos para a construção de seus palacetes. Os estilos assemelhavam-se ao que havia de mais importante na época e, muitas vezes, deixavam o próprio espírito criativo se manifestar nas edificações sendo notável o ecletismo arquitetônico. (RISCHITELI, 2005)

A constatação do autor é compartilhada por Heliana Salgueiro que, ao caracterizar a evolução da arquitetura, observa que com o fomento econômico da indústria zebuína, as construções se requintaram, chegando ao apogeu nos anos 1920, quando a peste bovina encerrou as importações de gado, interrompendo o comércio e iniciando uma nova fase de crise econômica (SALGUEIRO, 1984). Tanto na zona rural quanto na zona urbana, as construções tinham um aspecto magnificente para não só demonstrar o poderio econômico de seu proprietário, também sinalizar o apuro civilizacional que ia se constituindo na cidade.

Considerando que a cidade possuía as bases necessárias para se tornar destaque na região e também no país, as elites uberabenses consideraram que a questão da educação possuía um patamar de altíssima importância, visto o reconhecido papel do ensino na formação do povo para o exercício da cidadania e a civilidade.

Esse debate, no entanto, não estava restrito apenas à cidade de Uberaba e perpassou a própria organização do Estado Republicano. Segundo Carvalho e Gonçalves Neto (2005), na Constituição de 1891 a questão educacional aparece, mas, a única definição encontrada no texto é que seria responsabilidade dos estados organizarem o ensino escolar.

Em Minas Gerais, ainda com Carvalho e Gonçalves Neto (2005), na Constituição Estadual de 1892, a questão também é citada, sendo que o estado mineiro transfere a responsabilidade aos municípios, sob a alegação de que faltavam verbas ao governo estadual para o suprimento da demanda.

Para compreender de que forma as municipalidades colocaram em prática esse trabalho, passaremos agora a analisar as atas da Câmara Municipal de Uberaba de 1899 a 1908.

\section{As fontes e a organização da educação em Uberaba}

Fontes privilegiadas por apresentarem resumos nem sempre sintéticos do debate e dos ideais presentes no contexto político da cidade na época, as atas da Câmara Municipal apresentam indícios que nos permitem tecer algumas considerações acerca da relação entre prática e discurso em torno da educação no período da Primeira República na cidade de Uberaba.

Partindo das atas foi possível observar que os três primeiros anos após a proclamação da República foram tomados pelas formalidades da transição política, com a dissolução da Câmara e a formação de uma comissão que se encarregou da organização administrativa da cidade para a realidade republicana. Nesse momento, não havia espaço 
para discussões relativas às questões da educação e não encontramos qualquer menção nesse sentido.

Após esse processo, começaram a aparecer no cotidiano da Câmara, as primeiras discussões acerca do ensino no contexto republicano. De forma geral, a atuação da Câmara na organização de um sistema de ensino público na cidade de Uberaba se restringiu a três aspectos principais: a criação de escolas, a nomeação e a remuneração de professores, e a administração de recursos para o ensino.

Aspecto mais frequente no cotidiano da Câmara uberabense, a criação de escolas é assunto tratado em várias das atas consultadas. Intentando facilitar a mobilização do conteúdo dessa documentação consultada, optamos pela sua sistematização nas atas a seguir:

\begin{tabular}{|c|c|c|c|c|c|c|c|c|c|c|c|c|}
\hline \multicolumn{13}{|c|}{ Tabela 1 - Escolas Rurais } \\
\hline Escola & $\begin{array}{c}189 \\
3\end{array}$ & $\begin{array}{c}189 \\
4\end{array}$ & $\begin{array}{c}189 \\
5\end{array}$ & $\begin{array}{c}189 \\
6\end{array}$ & 1897 & $\begin{array}{c}189 \\
8\end{array}$ & $\begin{array}{c}189 \\
9\end{array}$ & 1900 & 1901 & 1902 & 1903 & 1904 \\
\hline Fazenda da Ponte Alta & $\mathrm{C}$ & & & & $\begin{array}{c}\mathrm{TS} \\
\mathrm{R}\end{array}$ & $\mathrm{T}$ & & & & 1802 & 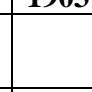 & \\
\hline Fazenda do Capão Fundo & & & & & & $\mathrm{C}$ & & & & & & \\
\hline Fazenda dos Dias & & & $\mathrm{C}$ & $\mathrm{T}$ & & & & & & & & \\
\hline Fazenda de São Franscisco & & & $\mathrm{T}$ & & & & & & & & & \\
\hline Fazenda do Barreiro & & & & & & & & & & & $\mathrm{T}$ & \\
\hline Fazenda do Pântano & & & & $\mathrm{T}$ & & & & & & & & \\
\hline $\begin{array}{l}\text { Fazenda de S. José do Capão da } \\
\text { Onça }\end{array}$ & & & & & & & & & & & $\mathrm{C}$ & \\
\hline Fazenda dos Telles & & & & & & $\mathrm{C}$ & & & & & & \\
\hline Escola Rural em São Félix & & & & $\mathrm{C}$ & & & & & & & & \\
\hline Fazenda do Veadinho & & & & & & & & & & & & $\mathrm{T}$ \\
\hline Fazenda da Cana Brava & & & & & & & & & & $\mathrm{C}$ & & \\
\hline \multicolumn{13}{|c|}{$\mathrm{C}=$ Criação; $\mathrm{T}=$ Transferência; $\mathrm{S}=$ Supressão; $\mathrm{R}=$ Restauração } \\
\hline \multicolumn{13}{|c|}{ Tabela 2 - Escolas Urbanas } \\
\hline Escola & & & & & $\begin{array}{c}189 \\
6\end{array}$ & $\begin{array}{c}189 \\
7\end{array}$ & 1898 & 1899 & 1900 & 1901 & 1902 & 1903 \\
\hline Bairro dos Estados Unidos & & & & & $\mathrm{C}$ & & & & & & & \\
\hline Liceu de Artes e Ofícios & & & & & & & & & & & $\mathrm{C}$ & \\
\hline \multicolumn{5}{|c|}{ Escola para o sexo masculino em S. Miguel do Veríssimo } & & & & & & & $\mathrm{C}$ & \\
\hline \multicolumn{5}{|c|}{ Escola Primária para o sexo masculino no Alto das Mercês } & & & & & & & $\mathrm{C}$ & \\
\hline \multicolumn{5}{|c|}{$\begin{array}{l}\text { Cadeira de Instrução Primária do sexo feminino no Arraial do } \\
\text { Veríssimo }\end{array}$} & & & & & & & & $\mathrm{C}$ \\
\hline \multicolumn{5}{|c|}{$\begin{array}{l}\text { Porto do Cemitério do Distrito de Dores do Campo Formozo - } \\
\text { sexo masculino }\end{array}$} & & & & $\mathrm{C}$ & & & & \\
\hline \multicolumn{5}{|c|}{$\begin{array}{l}\text { Escola do Sexo Masculino em Nossa Senhora D’Abadia dos } \\
\text { Dourados }\end{array}$} & & & & $\mathrm{C}$ & & & & \\
\hline \multicolumn{5}{|l|}{ Escola Mixta no Alto do Fabrício } & & & & & & & $\mathrm{C}$ & \\
\hline \multicolumn{5}{|c|}{ Escola primária no Bairro do Barro Preto } & & & & & & & & $\mathrm{C}$ \\
\hline \multicolumn{5}{|c|}{$\begin{array}{l}\mathrm{C}=\text { Criação; } \mathrm{T}=\text { Transferência; } \mathrm{S}=\text { Supressão; } \mathrm{R}=\text { Restauração } \\
(\mathrm{APU})\end{array}$} & & & & o Públic & & beraba & & \\
\hline
\end{tabular}


Ao longo dos vinte anos, entre 1889 e 1908, foram criadas sete escolas rurais e nove escolas urbanas, contabilizando dezesseis escolas criadas na cidade. Espalhadas pela região, as escolas rurais eram instaladas em áreas onde houvesse demanda como em sedes de fazendas ou em núcleos populacionais que posteriormente dariam origem a algumas cidades da região. As escolas urbanas seguiam a mesma lógica da quantidade de alunos atendidos, sendo geralmente instaladas em bairros mais populosos ou em áreas centrais da cidade.

Embora as atas revelem a criação de um número significativo de escolas para uma população que contava, em 1900, com mais de vinte mil habitantes (Rezende, 1991) não se pode afirmar com certeza que todas elas tenham funcionado. É possível aventar que as limitações orçamentárias tenham impedido a criação efetiva das classes. Por outro lado, o número de escolas também é denotativo do modo como os políticos e as frações de grupos sociais neles representados, apropriaram-se do discurso de valorização da educação como estratégia para se inserir nos novos tempos considerados modernos.

Como podemos observar na tabela 1, havia uma frequente transferência dessas escolas. Isso se dava por vários motivos, especialmente a busca por uma localidade mais povoada que permitisse a frequência do maior número de alunos possível. Um caso interessante é a escola da Fazenda Ponte Alta.

Criada em 9 de setembro de 1893, foi instalada provavelmente no ano seguinte, como podemos observar:

[Ordem do Dia] A Comissão de Legislação aqui foi encarregada a dar parecer sobre o projeto de lei que cria uma escola na Fazenda da Ponte Alta deu um parecer favorável mandando-o para que seja considerado no futuro orçamento a quota de sua despeza. (Ata da Câmara Municipal de Uberaba da Sessão Ordinária do dia 18 de setembro de 1893)

Em 1897, foi proposta sua transferência:

Foi apresentada uma indicação do vereador Carlos da Cunha no sentido de transferir-se a escola da Fazenda da Ponte Alta onde não há freqüência legal de alunnos para a Fazenda da Conceição das Alagoas do districto do Garimpo. Deliberou a Câmara não a transferência e sim a supressão da dita escola em vista da falta de presença legal de alunnos e porque na fazenda acima referida não há escola creada, isto contra o voto do vereador Odorico Silva. (Ata de Sessão Ordinária da Câmara Municipal de Uberaba do dia 22 de novembro de 1897)

Após três sessões debatendo a matéria, a Câmara aprovou a supressão da escola da Ponte Alta.

Entraram em seguida em terceira e última discussão os projectos sobre a creação de uma escola rural na fazenda das Alagoas districto de Conceição das Allagôas e supressão da escola da Fazenda da Ponte Alta deste município (...) sendo (...) approvado contra os votos dos Sñrs vereadores Odorico Silva, João de Aquino e Teophilo de Medeiros (...) (Ata de Sessão Ordinária da Câmara Municipal de Uberaba do dia 24 de novembro de 1897)

No dia 06 de janeiro de 1898, a referida escola voltou ao debate na Casa.

[Ordem do Dia] Leu-se o parecer da commissão de instrucção pública sobre o requerimento em que o cidadão Manoel Barcellos pede a restauração da Escola Municipal da Fazenda da Ponte Alta declarando a 
commissão não poder estudar com segurança a questão enquanto não lhe forem fornecidas pelo sñr presidente as seguintes informações:

a)Tem tido a escola freqüência legal;

b)Quantos alunnos do município do Sacramento a freqüentam e quantos de Uberaba (Ata da Sessão Ordinária da Câmara Municipal de Uberaba do dia 06 de janeiro de 1898)

Sendo então restaurada, novamente a escola da Ponte Alta entrou em pauta, com a sugestão de uma nova transferência:

[Expediente] Projecto de Lei do mesmo vereador, justificando a conveniência de se transferir para Capão Fundo lugar populoso do município a escola municipal de Ponte Alta, era suspensa por falta de concorrência" (Ata da Sessão Ordinária da Câmara Municipal de Uberaba do dia 9 de março de 1898)

Em todo processo foi visível o desacordo entre os vereadores com relação à transferência da escola, com a abstenção do voto por aqueles que representavam ou estavam de alguma forma ligados à localidade em questão.

O caso da Fazenda da Ponte Alta nos ajuda pensar o valor da educação nas áreas rurais e a importância dada à continuidade nos estudos vista na dificuldade de se manter a frequência de alunos. Provavelmente estimulados pela valorização do ensino existente naquele momento, havia uma grande demanda pelas escolas, mas também, a realidade do trabalho no campo, que demandava certa dedicação dos alunos, era um fator que dificultava a permanência. Ainda, o reconhecimento da importância do letramento poderia não significar a conclusão dos estudos, bastando a alfabetização.

Já com a análise dos dados da tabela 2, podemos inferir que havia uma maior estabilidade no caso das escolas urbanas. Também, é possível identificar a preocupação com o ensino primário, compreendido como o processo de alfabetização, e a aceitação de modelos diversos de funcionamento das escolas, como as escolas mistas e as escolas específicas para meninos ou meninas. Ainda é importante ressaltar a permanência das cadeiras isoladas, utilizado desde a expulsão dos jesuítas do país, que sobrevivia num contexto de debate de formulação de um sistema escolar nacional. (MACIEL; SHIGUNOV NETO, 2006) Outro ponto a se pensar é a real instalação dessas escolas, uma vez que a edificação destas estava limitada à disponibilidade de verbas para sua realização.

Porém, a única necessidade enfrentada não era a construção de escolas, havia também a necessidade de professores. A necessidade de pessoas com a qualificação necessária e interesse pelo cargo de professores. Na ata referente à Sessão Ordinária do dia 02 de maio de 1893, foi aprovada a nomeação de professores pela Câmara uma vez que não houve candidatos para concurso público realizado para esse fim.

A situação desses professores, por sua vez se achava intimamente ligada à permanência ou não das escolas/cadeiras e, no caso de transferência, deveriam "acompanhar" a escola. Desses professores era cobrada uma conduta irrepreensível; no ato da posse ao cargo eles deviam demonstrar além de suas habilidades acadêmicas, características morais comprováveis entre outras coisas por meio de um relatório do pároco local e certificado de batismo. Em especial no caso das mulheres, a conduta era extremamente observada, chegando mesmo a proibição de sua atuação profissional caso fosse deixada pelo marido, ou restrições em períodos de gestação. Se fosse solteira, era necessário que ela comprovasse a aprovação do pai. (BORGES, 2005)

Nesse contexto, é possível também inferir que a nomeação de professores era utilizada em barganhas políticas, uma vez que em várias atas estavam explícitos os debates 
relativos a essas nomeações, com vetos e nomeação de mais de um professor para a mesma vaga. Como na ata da Sessão Ordinária do dia 05 de Abril de 1904:

[Indicações] Uma assignada pelo vereador Eugenio Oscar pedindo a nomeação do cidadão José Rodrigues da Cunha para professor da escola do Barro Preto desta cidade, uma outra assignada pelos vereadores Lucas Borges e Tobias de Carvalho pedindo a nomeação do cidadão José de Araújo Vas de Mello também como professor da mesma escola

[Ordem do Dia] O Sñr Presidente submeteu a descução a indicação apregoada pelos vereadores Lucas Borges e Tobias de Carvalho sobre a nomeação do professor José de Araújo Vas de Mello e ninguém pedindo a palavra, o Sñr Presidente a submeteu a votação e verificou-se a negação da mesma por grande maioria dos votos. Em seguida foi submetida a indicação apregoada pelo vereador Eugenio Oscar, como também ninguém pedindo a palavra, o Snr Presidente a submeteu a votação, verificando-se a aceitação do Snr João Rodrigues da Cunha para professor da escola do Barro Preto desta cidade por grande maioria dos votos.

Também, é importante ressaltar o período entre os anos de 1902 a 1904, como momento que esse debate esteve mais presente, como explicitado na tabela 3, a seguir:

\begin{tabular}{|c|c|c|c|c|c|c|c|c|c|c|c|c|c|c|}
\hline \multicolumn{15}{|c|}{ Tabela 3 - Professores } \\
\hline Situacz̃o Ano & 1892 & 1893 & 1894 & 1895 & 1896 & 1897 & $\begin{array}{c}189 \\
8 \\
\end{array}$ & 1899 & 1900 & 1901 & 1902 & 1903 & 1904 & 1905 \\
\hline Indicação & & & & & 1 & & & 2 & & & 11 & 7 & 5 & 1 \\
\hline Transferência & & & & 1 & 1 & & 1 & & & & 1 & 5 & 1 & \\
\hline Demissão & 1 & & & & 2 & & & & & & & 2 & 2 & 1 \\
\hline
\end{tabular}

É de destaque que essas nomeações e transferências de professores levaram a Casa legislativa a regularizar a situação, com o artigo primeiro da Lei ${ }^{\circ} 9$ de 5 de maio de 1893 , o qual determinava que a "nomeação e demissão de professores municipaes quer definitivos quer interinos competem exclusivamente à Câmara Municipal".

Além da nomeação, a Câmara se responsabilizava diretamente pela remuneração dos professores que atuavam na cidade. Em várias atas do período podem ser encontrados os requerimentos reivindicando pagamento regular e gratificações por serviços prestados.

Entre os principais motivos de gratificação aos professores estava a presença frequente e de uma boa quantidade de alunos por turma/escola. Como o relatado na ata da Vigésima Primeira Sessão Extraordinária do dia 2 de setembro de 1901, a professora D. Laurinda Augusto de Moura fez o requerimento:

[...] pedindo uma gratificação atenta ao grande accumulo de serviços que ela tem no exercício do cargo de professora da Escola Mixta Municipal desta cidade, demonstrando a elevada freqüência de sessenta alunnos que aquelle estabelecimento manteve durante o mês de agosto (Ata da Vigésima primeira Sessão Extraordinária, de 2 de setembro de 1901).

Essa negociação direta com a Câmara era mediada pela existência de verba disponível para a educação, uma vez que em momentos de dificuldades financeiras não se hesitava em cortar qualquer projeto ou indeferir algum pedido dos professores. Também, é interessante a ausência de um padrão em relação à forma e ao valor do pagamento dos 
docentes, visto que alguns recebiam mensalmente, outros anualmente e ainda havia casos em que o professor recebia pela quantidade de alunos 'educados'. Isso também poderia evidenciar o caráter circunstancial da preocupação que o poder público dispensava à educação escolar.

Ainda em relação à administração de recursos é possível observar que não era incomum o adiamento da criação de escolas e liberação de recursos para o exercício seguinte, uma vez que nem sempre essas demandas eram previstas no planejamento orçamentário do município. Isso fazia com que a instalação de novas escolas demorasse até mesmo anos, até que a Casa se encontrasse em condições de realizar tal obra. E isso num momento em que várias escolas foram criadas por meio de requisição popular, que se organizava em abaixo-assinados como no caso da escola do sexo masculino criada no bairro Estados Unidos (Ata da Sessão Ordinária do dia 8 e janeiro de 1902):

É lida uma representação de oitenta e oito moradores do Bairro dos Estados Unidos, pedindo a criação de uma escola nesse lugar, destinada ao sexo masculino e recommendo para seu professor o cidadão Tenete Joaquim Flávio de Lima, pedem que o referido professor seja taxado o ordenado de um conto e quatrocentos mil réis (...)

Outro exemplo desta manifestação popular está presente na Ata de Sessão Ordinária da Câmara Municipal do dia 7 de Maio de 1894:

[Expediente] Foi apresentado e lido um abaixo assignado de diversos cidadãos residentes na Fazenda dos Moreiras pedindo para que esta Câmara conserve a escola municipal na referida Fazenda, propondo a fazerem gratuitamente a caza em lugar concernente para a aula na divisa das duas fazendas ficando assim divididas as distancias para freqüência dos alunos.

Esses fragmentos nos permitem entender que em grande medida a valorização da educação era partilhada entre a população e que esta estava interessada em garantir sua difusão. Também, mostra que os abaixo-assinados eram meios importantes de reivindicação, o que é interessante no sentido da atuação da população no governo. Ainda, a utilização do abaixo-assinado permite inferir que era realizado por pessoas já alfabetizadas que naquele momento eram representados por membros das elites, visto que a maior parte da população ainda não tinha acesso à educação.

Outra questão relacionada à gestão dos recursos na cidade era a manutenção das escolas criadas, que nem sempre possuíam condições adequadas para a existência das turmas e ainda, certa indistinção entre o público e o privado, que pode ser observado no caso da requisição de auxílio para o serviço de esgoto do "Collegio Uberabense", reconhecida escola particular da cidade:

“[Indicação] Idem do Sñr Irmão Gandulpho pedindo auxílio de quatro contos para ocorrer às despesas com esgottos e captação de águas ao serviço do Collegio que dirige." (Ata da Sessão Ordinária da Câmara Municipal de Uberaba do dia 15 de setembro de 1903)

Essa requisição foi aprovada e entrou para o projeto de orçamento do ano seguinte, no valor de mil e quinhentos réis. Porém, esse auxílio foi questionado:

"Idem sobre a lei do orçamento para o exercício de 1904, commentando os seguintes pontos: (...) b) Julga injusto o auxílio de 1:500.000 ao Collégio Uberabense por ser um estabelecimento particular e que aufere lucros não pequenos e que não dá ensino gratuito à meninos pobres acrescendo que a câmara não deve proporcionar serviços de águas (...)" 
(Ata de Sessão Ordinária da Câmara Municipal de Uberaba de 4 de dezembro de 1903)

\section{Considerações Finais:}

Momento reconhecido como importantíssimo à formação do Brasil enquanto nação e de grandes transformações em âmbito mundial, os últimos anos do século XIX e primeiras décadas do século XX foi uma época de grande importância para a organização de um sistema de educação escolar no país.

Como visto na análise dos excertos das atas da Câmara Municipal de Uberaba, aqui selecionados e apresentados, o discurso que valorizava a educação e que reconhecia na escola o grande motor das transformações que queriam para o país, naquele período, encontrava uma série de dificuldades para sua efetivação. A principal delas era a ausência e o mau uso dos recursos financeiros que castigavam a administração pública na cidade e que em vários momentos impediram a realização de obras que eram necessárias e de uma implementação mais efetiva da escolarização em Uberaba.

Outro ponto a ser considerado é a questão da densidade populacional, uma vez que grande parte da população morava no campo e, não estava distribuída de forma homogênea. Isso complicava a definição de uma melhor localização para as escolas criadas o que, como nos casos relatados no item anterior, levaram mesmo a extinção da escola/cadeira pela ausência de alunos em determinado local.

Também, a indefinição de um modelo foi uma grande questão nesse período, que complicavam a efetivação da difusão do ensino, bem como a ausência de professores habilitados à atuação.

Por fim, a centralização da administração dos recursos da educação pela Câmara Municipal de Uberaba era um fator que facilitava o uso indevido dessas verbas, como no caso do "Collegio Uberabense" (entidade privada de ensino da cidade) e, também, que as questões relativas ao ensino se diluíssem em meio às diversas outras questões inerentes à administração pública.

\section{Referências:}

ARQUIVO PÚBLICO DE UBERABA. Fundo Câmara Municipal de Uberaba, Atas da Câmara Municipal de Uberaba. 1889-1908.

BORGES, Vera Lúcia. Subsídios para a história da formação docente no Brasil. Minas Gerais. (1892-1930). In: GATTI Jr. Décio \& INÁCIO FILHO, Geraldo (orgs) História da Educação em Perspectiva. Campinas: Autores Associados/Uberlândia: Edufu, 2005. pp.227-262.

CAMPOS, Raquel Discini de. A "Princesa do Sertão" na modernidade republicana: urbanidade e educação na Rio Preto dos anos 1920. São Paulo: Annablume; São José do Rio Preto: Secretaria Municipal de Cultura, 2004.

GONÇALVES NETO, Wenceslau \& CARVALHO, Carlos Henrique. O nascimento da educação republicana: princípios educacionais nos regulamentos de Minas Gerais e Uberabinha (MG) no final do século XX. In: GATTI Jr. Décio \& INÁCIO FILHO, Geraldo (orgs) História da Educação em Perspectiva. Ensino, pesquisa, produção e 
novas investigações. Campinas: Autores Associados/Uberlândia: Edufu, 2005. pp.263294.

MACIEL, Lizete S. B.; SHIGUNOV NETO, Alexandre. A educação brasileira no período pombalino: uma análise histórica das reformas pombalinas do ensino. Educação e Pesquisa, São Paulo, v.32, n.3, p. 465-476, set./dez. 2006

REZENDE, Eliane Mendonça Márquez. 1811-1910 Uberaba: Uma trajetória sócioeconômica. Uberaba: Arquivo Público de Uberaba, 1991.

RISCHITELI, Augusto B. S. P. Imagens e vozes do Sertão da Farinha Podre na produção historiográfica de Antonio Borges Sampaio. (1880 - 1908). Franca: FHDSS/Unesp, 2005. (Dissertação de Mestrado em História Social).

SALGUEIRO, Heliana Angotti. Apontamentos para um estudo de arquitetura regional: ecletismo do zebu em Uberaba. Estudos. Vol.11, n³/4. Goiânia: UCG, 1984. pp. 207-224.

Recebido em outubro-12

Aprovado em maio-13

Notas

${ }^{1}$ O presente artigo é resultado do trabalho de Iniciação Científica desenvolvido na Universidade Federal do Triângulo Mineiro (UFTM) e integra o projeto de pesquisa interinstitucional Descentralização do ensino $e$ ação municipal na educação brasileira: análise de alguns municípios de Minas Gerais no início da República (1889-1906) e que envolve várias IES mineiras.

${ }^{2}$ Graduando em História - jean.borges88@gmail.com e Professora Adjunta do Departamento de História da UFTM sandramdantas@hotmail.com .

${ }^{3}$ Todas as tabelas aqui apresentadas foram elaboradas a partir dos dados compulsados nas atas da Câmara Municipal de Uberaba, disponíveis no Arquivo Público de Uberaba (APU). 